\title{
Comparison of Costs and Safety of a Suture-Mediated Closure Device With Conventional Manual Compression After Coronary Artery Interventions
}

\author{
Hans Rickli, ${ }^{1 *}$ MD, Martin Unterweger, ${ }^{2} \mathrm{MD}$, Gabor Sütsch, ${ }^{3} \mathrm{MD}$, \\ Hans Peter Brunner-La Rocca, ${ }^{3}$ MD, Markus Sagmeister, ${ }^{1}$ MD, \\ Peter Ammann, ${ }^{1}$ MD, and Franz W. Amann, ${ }^{3}$ MD
}

\begin{abstract}
The aim of this study was to assess costs and safety of immediate femoral sheath removal and closure with a suture-mediated closure device (Perclose, Menlo Park, CA) in patients undergoing elective ( $\mathrm{PCl}$ ). A total of 193 patients was prospectively randomized to immediate arterial sheath removal and access site closure with a suture-mediated closure device (SMC; $n=96$ ) or sheath removal $4 \mathrm{hr}$ after $\mathrm{PCl}$ followed by manual compression (MC; $\mathrm{n}=97$ ). In the SMC group, patients were ambulated $4 \mathrm{hr}$ after elective $\mathrm{PCl}$ if hemostasis was achieved. In the MC group, patients were ambulated the day after the procedure. In addition to safety, total direct costs including physician and nursing time, infrastructure, and the device were assessed in both groups. Total direct costs were significantly (all $P<0.001$ ) lower in the SMC group. Successful hemostasis without major complication was achieved in all patients. The time to achieve hemostasis was significantly shorter in the SMC group $(7.1 \pm 3.4$ vs. $22.9 \pm 14.0 \mathrm{~min} ; P<0.01)$ and $85 \%$ of SMC patients were ambulated on the day of intervention. Suture-mediated closure allows a reduction in hospitalization time, leading to significant cost savings due to decreased personnel and infrastructural demands. In addition, the use of SMC is safe and convenient to the patients. Cathet Cardiovasc Intervent 2002;57:297-302.

๑ 2002 Wiley-Liss, Inc.
\end{abstract}

Key words: costs; arterial puncture site; access site; vascular closure device; cardiac catheterization

\section{INTRODUCTION}

The femoral artery is the access site most frequently used to perform catheter-based vascular interventions. Management of the femoral arterial puncture site relies mainly on manual compression, which is associated with prolonged bed rest and significant patient discomfort. Moreover, up to $10 \%$ of patients complain of significant local complications such as hematoma and false aneurysms leading in $1 \%-2 \%$ to vascular surgical intervention or transfusion [1-3]. The complication rate may depend on the operator's experience, type of intervention, and duration of manual compression [4]. Therefore, new methods to achieve hemostasis have been developed. One of these uses collagen to manage access site closure, i.e., VasoSeal (Datascope, Montvale, NJ [5-7]), Angioseal (Sherwood Medical, Bothell, WA [8-10]), and Duett (Vascular Solution, Minneapolis, MN $[9,11]$ ). Alternatively, a percutaneous suturing device (Techstar, Perclose, Redwood City, CA) allows surgical closure of the femoral artery with little trauma to the overlaying tissue $[12,13]$. Suture-based closure has been shown to be safe and effective to achieve immediate hemostasis and early ambulation without increasing the risk of bleeding complications $[14,15]$. However, the impact of this new device on costs for the health care system and the patient's preference have not been evaluated.

\section{MATERIALS AND METHODS}

We performed a single-center, multiple-operator, prospective study in 193 patients undergoing elective per-

\footnotetext{
${ }^{1}$ Department of Clinical Medicine, Division of Cardiology, Kantonsspital, St. Gallen, Switzerland

${ }^{2}$ Department of Radiology, Institute of Diagnostic Radiology, University Hospital Zürich, Zürich, Switzerland

${ }^{3}$ Department of Internal Medicine, Division of Cardiology, University Hospital Zürich, Zürich, Switzerland
}

*Correspondence to: Hans Rickli, Kardiologie, Kantonsspital, $\mathrm{CH}-$ 9007 St. Gallen, Switzerland. E-mail: hans.rickli@kssg.ch

Received 8 March 2002; Revision accepted 3 May 2002

DOI 10.1002/ccd.10294

Published online in Wiley InterScience (www.interscience.wiley.com). 
cutaneous coronary intervention (PCI) using a 6 or $7 \mathrm{Fr}$ femoral access. At the end of the PCI, patients were randomized to undergo either suture-mediated closure (SMC; group $\mathrm{A}, \mathrm{n}=96$ ) or conventional compression therapy (group B, $\mathrm{n}=97$ ). The hospital ethics committee had reviewed and approved the study protocol. All patients gave written informed consent prior to participation in the study.

Adjusted to the size of the procedural sheath, we used 6 and 7 Fr devices (Techstar XL, Perclose, Redwood City, CA). The SMC device operates as a monorail system and is designed to close femoral artery access sites from 6 to $10 \mathrm{Fr}$ in size regardless of anticoagulation levels, as previously described in detail [13]. In brief, an arterial back bleeding through a marker lumen indicates appropriate device positioning. Maintaining this position, two needles attached to a suture loop are percutaneously deployed through the vessel wall around the arteriotomy and into the barrel of the instrument by pulling on the device handle. Tissue approximation by delivering the tied suture with a special knot pusher directly on top of the vessel wall through the subcutaneous tissue establishes immediate hemostasis. Ambulation is possible within 2 to $4 \mathrm{hr}$.

For patients assigned to SMC, the procedure was performed immediately after the end of the PCI. Four operators trained in SMC (each operator had performed at least $50 \mathrm{SMC}$ procedures prior to initiation of the present study) performed all the procedures. If ongoing bleeding was present at the puncture site after SMC, manual or mechanical compression was allowed. If no bleeding was present, a light bandage was applied. Patients were allowed to ambulate $4 \mathrm{hr}$ later, provided there was no bleeding at the femoral access site. In patients assigned to conventional manual compression (MC), the femoral sheath was removed $4 \mathrm{hr}$ after the PCI and manual compression was used to achieve hemostasis followed by additional local compression for $6 \mathrm{hr}$. MC patients were ambulated the following morning.

Patients were examined clinically and by Doppler ultrasound [15]. Additionally, the patients' discomfort was evaluated before discharge. A visual analogue scale, graded from 0 (best) to 10 (worst), was used to measure local pain due to the suture-based intervention, sheath removal, local compression, back pain, problems with urination, and groin pain during follow-up of 3 months. Additionally, a survey was conducted on patients' preference if they had had an earlier experience of a technique other than the one to which they were randomized.

Safety assessment included the occurrence of major (need for surgical intervention, local infection, need of blood transfusion) and minor complications (pseudoaneurysm, local hematoma $>1 \mathrm{ml}$ assessed by ultrasound). Assessment of efficacy included time to hemostasis, time

\section{TABLE I. Cost Elements}

\begin{tabular}{lrr}
\hline & $€$ & \multicolumn{1}{c}{$\$$} \\
\hline Catheterization laboratory per hour & 348.2 & 305.7 \\
Extra inpatient day & 627.3 & 550.8 \\
Perclose 6/7 Fr & 225.4 & 197.9 \\
Physician costs per hour & 91.7 & 80.5 \\
Nurse costs per hour & 41.3 & 36.3 \\
\hline
\end{tabular}

to ambulation, and time to hospital discharge. Time to hemostasis was measured from pulling out the femoral sheath until the bandage was applied after achieved hemostasis.

The cost analysis was restricted to costs related to the post-PTCA management (cost-minimization study). Total direct costs were calculated (costs of the SMC device, infrastructure and personnel costs) from the perspective of the institution for the year 2000. Costs of the catheterization room, costs of hospitalization, and personnel costs were derived form a special analysis of the accounting department of the University Hospital Zürich (data not shown). Costs are given in Euro (exchange rate: 1 Euro $=1.477 \mathrm{sFr}[$ October 2000] $=\$ 0.878$ USD $[$ December 2001]; Table I).

\section{Statistical Analysis}

Data are expressed as frequency and mean \pm standard deviation, respectively. Comparison between SMC and MC were analyzed by student's $t$-test, Mann-Whitney U-test, or Fisher's exact test as appropriate. Interactions between PCI and the two groups were tests using multivariate ANOVA for repeated measures. All calculations were performed using a commercially available statistical program (SPSS 9.0).

\section{RESULTS}

Baseline characteristics are given in Table II. Although there were no significant demographic differences between the two groups, patients in the SMC group had slightly but significantly lower hemogloblin levels before PCI. In the SMC group, a higher percentage of larger sheaths were used.

Efficacy and safety results of the study group are shown in Table III. Successful hemostasis without major complications was achieved in all patients in both groups. The mean decrease in hemoglobin was relatively small and similar in both groups $(0.63 \pm 0.98 \mathrm{~g} / \mathrm{dl}$ in the SMC group vs. $0.56 \pm 0.94 \mathrm{~g} / \mathrm{dl}$ in the MC group; $P=$ 0.61). There was also no difference between the two groups regarding minor complications. Both pseudoaneurysms observed were small and successfully treated with local compression. The use of the SMC device was associated with a significant reduction in time to achieve 
TABLE II. Baseline Characteristics

\begin{tabular}{lccc}
\hline & SMC $(\mathrm{n}=96)$ & MC $(\mathrm{n}=97)$ & $P$ \\
\hline Men & $71(74 \%)$ & $81(84 \%)$ & 0.12 \\
Age (years) & $62 \pm 11$ & $59 \pm 10$ & 0.07 \\
Body mass index $\left(\mathrm{kg} / \mathrm{m}^{2}\right)$ & $26.7 \pm 4.0$ & $27.3 \pm 4.0$ & 0.26 \\
Stent implanted at & & & \\
$\quad$ intervention & $73(76 \%)$ & $62(64 \%)$ & 0.08 \\
Heparin (IU) & $15,359 \pm 3,837$ & $15,448 \pm 3,586$ & 0.87 \\
Hemoglobin before PCI & & & \\
$\quad$ (g/dl) & $13.2 \pm 1.4$ & $13.9 \pm 1.2$ & 0.001 \\
Aspirin before PCI & $92(96 \%)$ & $96(99 \%)$ & 0.21 \\
Ticlopidin before PCI & $10(10 \%)$ & $4(4 \%)$ & 0.10 \\
Aspirin after PCI & $96(100 \%)$ & $96(99 \%)$ & 1 \\
Ticlopidin after PCI & $74(77 \%)$ & $65(67 \%)$ & 0.15 \\
Coumadin after PCI & $3(3 \%)$ & $6(6 \%)$ & 0.50 \\
Multiple femoral punctures & $7(7 \%)$ & $4(4 \%)$ & 0.57 \\
Sheath size (6/7 Fr) & $39 / 57$ & $54 / 43$ & 0.05 \\
ACT after PCI (sec) & $286 \pm 92$ & $275 \pm 62$ & 0.36 \\
Duration of PCI (min) & $86 \pm 41$ & $85 \pm 37$ & 0.77 \\
\hline
\end{tabular}

TABLE III. Efficacy and Safety Results

\begin{tabular}{lccc}
\hline & $\begin{array}{c}\text { SMC } \\
(\mathrm{n}=96)\end{array}$ & $\begin{array}{c}\text { MC } \\
(\mathrm{n}=97)\end{array}$ & $P$ \\
\hline $\begin{array}{l}\text { Time to achieve hemostasis } \\
(\text { min) }\end{array}$ & $7.1 \pm 3.4$ & $22.9 \pm 14.0$ & $<0.001$ \\
$\begin{array}{l}\text { Time between PCI and } \\
\text { ambulation (hr) }\end{array}$ & $6.8 \pm 5.0$ & $18.4 \pm 2.1$ & $<0.001$ \\
$\begin{array}{l}\text { Decrease in hemoglobin (g/dl) } \\
\text { Decrease in hemoglobin } \\
>\text { 2g/dl }\end{array}$ & $0.63 \pm 0.98$ & $0.56 \pm 0.94$ & 0.61 \\
$\begin{array}{l}\text { Hematoma assessed by } \\
\text { ultrasound }\end{array}$ & $8(8 \%)$ & $6(6 \%)$ & 0.55 \\
$\begin{array}{l}\text { Pseudoaneurysm assessed by } \\
\text { ultrasound }\end{array}$ & $7(7 \%)$ & $5(5 \%)$ & 0.57 \\
\begin{tabular}{l} 
Major complication \\
\hline
\end{tabular} & $1(1 \%)$ & $1(1 \%)$ & \\
\hline
\end{tabular}

hemostasis $(7.1 \pm 3.4$ vs. $22.9 \pm 14.0 \mathrm{~min} ; P<0.001)$ and time to ambulation $(6.8 \pm 5.0$ vs. $18.4 \pm 2.1 \mathrm{hr} ; P<$ 0.001). Eighty-three patients $(85 \%)$ treated with SMC were successfully ambulated on the day of PCI. In the remaining 13 patients, there was continuous subcutaneous blood oozing, requiring a light compressive femoral bandage until the following morning. These patients, and the patients randomized to manual compression, could be ambulated successfully the day after PCI.

Patient discomfort immediately after PCI was significantly less in the SMC group (Table IV). However, groin pain during 3-month follow-up was worse in this group. No significant difference could be observed in groin pain during in-hospital follow-up $(3.4 \pm 1.7$ vs. $3.0 \pm 1.0$; $P=$ NS). Thirty-five of $46(76 \%)$ of the patients who experienced both techniques (SMC with earlier MC and vice versa) would prefer SMC as a future closure technique, whereas only 8 of $46(17 \%)$ would prefer MC $(P<0.001)$.

As depicted in Figure 1, total post-PCI costs were reduced in the SMC group as compared to the MC group
TABLE IV. Patient Discomfort*

\begin{tabular}{lccc}
\hline & SMC & MC & $P$ \\
\hline $\begin{array}{l}\text { Pain due to SMC, sheath removal, } \\
\quad \text { compression (0-10) }\end{array}$ & $1.7 \pm 2.2$ & $2.9 \pm 2.7$ & $<0.001$ \\
$\quad$ Back pain (0-10) & $2.8 \pm 2.7$ & $4.5 \pm 2.9$ & $<0.001$ \\
Urinal problems (0-10) & $1.2 \pm 1.8$ & $1.8 \pm 2.4$ & 0.05 \\
$\begin{array}{l}\text { Groin pain during follow-up } \\
\quad(0-10)\end{array}$ & $3.0 \pm 2.0$ & $2.0 \pm 2.2$ & $<0.001$ \\
\hline
\end{tabular}

*Cost for additional drugs such as sleeping pills, pain killers, and local anesthetics were minimal and did not differ between the two groups.

by $13 \% \pm 3 \%$ (SMC $469 \pm 145$ vs. MC $539 \pm 57$ Euro; $P<0.001)$. The additional costs for the Perclose device (225 Euro) were exceeded by savings of ward costs due an earlier discharge (SMC $178 \pm 132$ vs. MC $481 \pm 55$ Euro; $P<0.001$ ). Other advantages were observed regarding time spent by the cardiologist (SMC $13.8 \pm 5.4$ vs. MC $32.9 \pm 13.9 \mathrm{~min} ; P<0.001)$ and the caring nurses (SMC $6.9 \pm 3.5$ vs. MC $11.5 \pm 7.0 \mathrm{~min} ; P<$ 0.001 ), resulting in reductions of personnel costs (cardiologist: SMC $21 \pm 8$ vs. MC $50 \pm 21$ Euro; $P<0.001$; nurse: SMC $5 \pm 2$ vs. MC $8 \pm 5$ Euro; $P<0.001$ ).

\section{DISCUSSION}

To the best of our knowledge, this is the first prospective, randomized study investigating the cost impact of a suture-based closure of the femoral arterial access for PCI in comparison to conventional MC. It shows that despite the additional costs of the device, SMC reduced total costs significantly, mainly due to earlier discharge. Additionally, the device was time-saving for the interventional cardiologist and the nursing staff. In addition, our study confirms previous reports of the safety and efficacy of the device $[14,15]$. Finally, we found inconvenience for the patients to be reduced and the majority of the patients having experience with both methods would prefer SMC for future interventions.

Conventional post-PCI care of the femoral artery access site using manual compression can be clinically performed safely and effectively, but involves delayed sheath removal and bed rest usually until the day after the intervention. Suture-based closure has been shown to achieve immediate hemostasis and early ambulation. As the costs of medical care continue to rise, there is increasing interest in evaluating the costs of medical practices. One area that has received particular scrutiny in recent years is percutaneous coronary revascularization. In the United States alone, more than 300,000 percutaneous coronary revascularization procedures are performed each year. However, it is important to have equal clinical outcome to evaluate the cost minimization of these procedures. Shortening the time to hemostasis and 


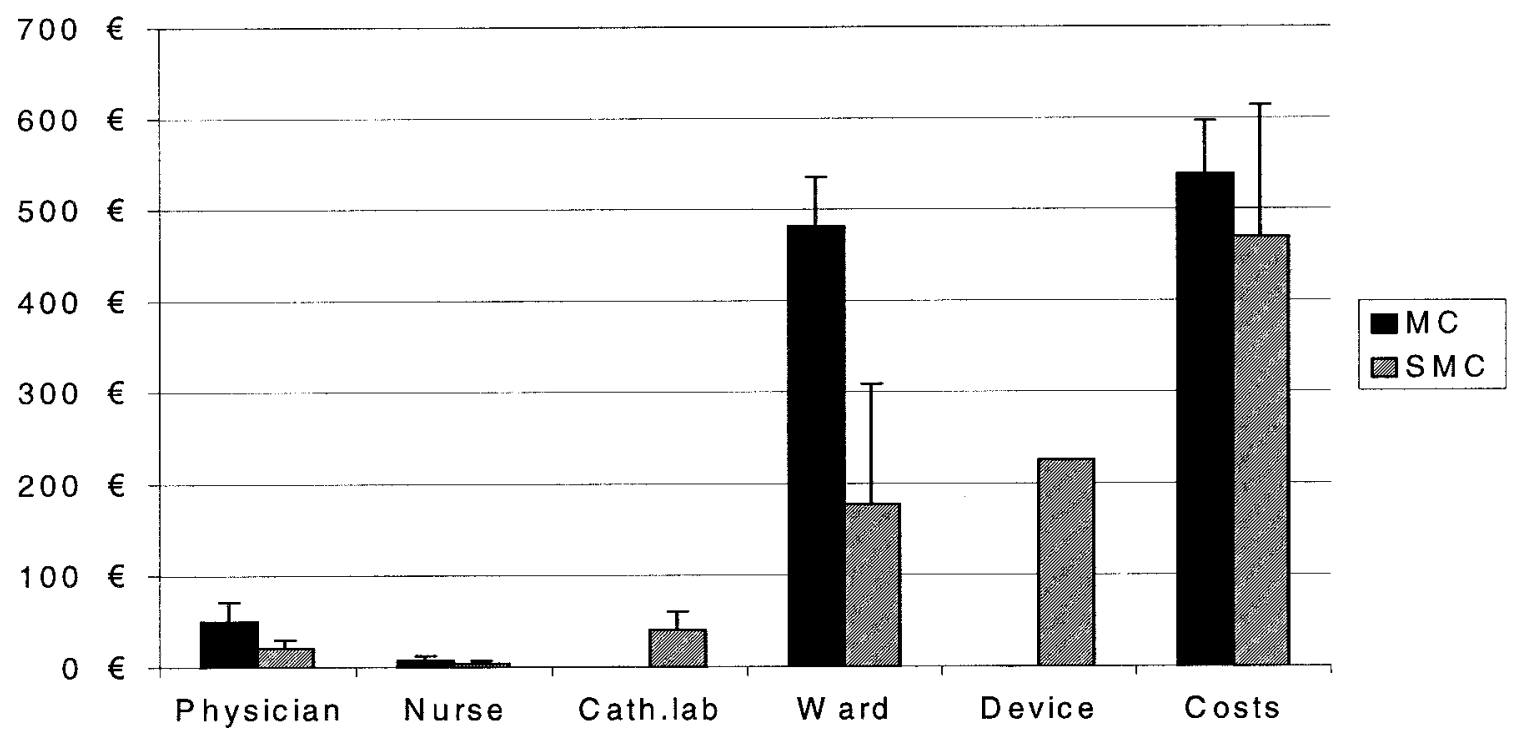

Fig. 1. Total costs including costs of the interventional physician, nurse, catheter laboratory, and the device in patients with manual compression and suture-mediated closure of the femoral arterial access for elective percutaneous coronary interventions in Switzerland.

ambulation represents a net benefit if the complication rate is not increased [16].

Clinical effectiveness and safety of suture-based closure have been evaluated in several clinical studies and are well documented $[14,15]$. Our study confirms these findings by observing only a few minor complications not affecting the patients' wellbeing significantly. No major complications occurred in either group. Even sonographic surveillance of the access site before ambulation and the day after intervention showed a small hematoma in only $7 \%$ of the patients, not requiring further intervention. The decrease in hemoglobin concentration was minimal in most patients and rarely exceeded $2 \mathrm{~g} / \mathrm{dl}$ in either group. Only in one patient in each group was a pseudoaneurysm found, which could be easily treated by local compression without relapse.

The major advantage of SMC is the immediate access closure, thus obviating the need for postprocedural hospitalization. Our study demonstrates that the use of SMC in patients undergoing elective PCI substantially reduces postprocedural length of hospital stay in comparison with MC, which may substantially reduce the procedural costs. Thus, average nonprocedural hospital costs have been estimated to be reduced from $\$ 900$ for transfemoral stenting to $\$ 300$ per patient with outpatient transradial stenting $[15,17]$. The economic benefit of outpatient elective coronary revascularization may depend crucially on the socioeconomic perspectives, including the insurance system of each country. Therefore, we calculated the direct institutional costs for manual compression and the suture-based closure, showing cost savings for the insti- tution with the use of suture-based closure. The full economic benefit, however, may be substantially larger.

Another important aspect of evaluating a new device is the potential impact on the patients' comfort. Apart from pain in the groin during follow-up, patient discomfort was reduced by SMC compared to MC. Accordingly, the majority of patients having experienced both methods would prefer SMC during a future intervention. This is in line with a recent report of a retrospective analysis of patient satisfaction with the suturing procedure [18]. They found a statistically significant patients' preference for SMC.

SMC is not the only technique using a device for hemostasis after PCI. Two other percutaneous hemostatic devices for femoral artery closure are available, using collagen plug closure (VasoSeal) or collagen sealing closure with an intra-arterial anchor (Angioseal). These devices have been reported to be safe and effective for closure of the access site in anticoagulated patients [19]. A comparison of a collagen plug closure device (VasoSeal) and an SMC device (Perclose) vs. assisted manual compression (Femostop) in PCI requiring abciximab revealed no differences between the different techniques with respect to safety and efficacy [20]. In a pilot study, a cohort of 50 patients was recruited to assess the feasibility of outpatient stenting with vascular sealing. Although there was no control group, the procedure was found to be safe. In addition, the cost savings using the 6 and $8 \mathrm{Fr}$ devices were estimated to be between $\$ 400$ and $\$ 500$ [21]. Together with our results, this may be interpreted that various closure devices may lead to signifi- 
cant cost savings as compared to conventional manual compression. However, a direct comparison with our study is not possible because of the lack of a control group [21]. As far as we are aware of, there are no reports about a direct comparison of the collagen-based closure devices and manual compression with respect to patients' preference and costs.

\section{Study Limitations}

In order to investigate safety and efficacy of the device, including clinical examination and ultrasound, SMC patients were not discharged from hospital as part of this study. However, patients were ambulated and not restricted in their movements. Thus, based on previous studies [15], immediate discharge from hospital is safe without further control.

Our cost analysis is derived from Swiss treatment patterns and Swiss cost structures. National cost studies are difficult to transfer to other countries with different health care systems. Therefore, we recalculated the potential cost savings for other countries to evaluate the transferability of our results. Thus, we used published cost elements from Germany [22] and the United States $[17,23]$. The assumed costs for the personnel and the use of the infrastructure varied considerably between these reports. Furthermore, the cost of the device varies between the three countries. Despite these differences of national cost elements, our results remained stable, showing significant cost savings of the SMC in comparison to the MC. Thus, the cost savings were slightly larger using the published cost elements form Germany (i.e., $\$ 85$ USD = 97 Euro, representing 15\% of the costs) [22], but exceeded the costs of our conservative calculation model significantly (i.e., \$411 USD = 468 Euro, representing $40 \%$ of the costs) using published data from the United States $[17,23]$. Therefore, it is very likely that our finding of the cost saving by the suture closure device is transferable to most first-world countries, where hospitalization is one of the main contributors to the total costs.

Suture-mediated closure of the femoral arterial access site for PCI compared with manual compression is costsaving and safe. Furthermore, the use of a suture-mediated closure device results in a statistically significant decrease in patient discomfort and is the technique preferred by most patients. Thus, suture-mediated closure devices may be used routinely in patients having femoral access for elective PCI.

\section{REFERENCES}

1. Kent KC, McArdle CR, Kennedy B, Baim DS, Anninos E, Skillman JJA. Prospective study of the clinical outcome of femoral pseudoaneurysms and arteriovenous fistulas induced by arterial puncture. J Vasc Surg 1993;17:125-131.

2. Kresowik TF, Khoury MD, Miller BV, Winniford MD, Shamma AR, Sharp WJ, Blecha MB, Corson JD. A prospective study of the incidence and natural history of femoral vascular complications after percutaneous transluminal coronary angioplasty. J Vasc Surg 1991;13:328-333.

3. Skillman JJ, Kim D, Baim DS. Vascular complications of percutaneous femoral cardiac interventions: incidence and operative repair. Arch Surg 1988;123:1207-1212.

4. Katzenschlager R, Ugurluoglu A, Ahmadi A, Hulsmann M, Koppensteiner R, Larch E, Maca T, Minar E, Stumpflen A, Ehringer $\mathrm{H}$. Incidence of pseudoaneurysm after diagnostic and therapeutic angiography. Radiology 1995;195:463-466.

5. Brachmann J, Ansah M, Kosinski EJ, Schuler GC. Improved clinical effectiveness with a collagen vascular hemostasis device for shortened immobilization time following diagnostic angiography and percutaneous transluminal coronary angioplasty. Am J Cardiol 1998;81:1502-1505.

6. Ernst, SM, Tjonjoegin RM, Schrader R, Kaltenbach M, Sigwart U, Sanborn TA, Plokker HW. Immediate sealing of arterial puncture sites after cardiac catheterization and coronary angioplasty using a biodegradable collagen plug: results of an international registry. J Am Coll Cardiol 1993;21:851-855.

7. Sanborn TA, Gibbs HH, Brinker JA, Knopf WD, Kosinski EJ, Roubin GSA. Multicenter randomized trial comparing a percutaneous collagen hemostasis device with conventional manual compression after diagnostic angiography and angioplasty. J Am Coll Cardiol 1993;22:1273-1279.

8. Aker UT, Kensey KR, Heuser RR, Sandza JG, Kussmaul WG. Immediate arterial hemostasis after cardiac catheterization: initial experience with a new puncture closure device. Cathet Cardiovasc Diagn 1994;31:228-232.

9. Henry M, Amor M, Allaoui M, Tricoche OA. New access site management tool: the angio-seal hemostatic puncture closure device. J Endovasc Surg 1995;2:289-296.

10. Kussmaul WG, Buchbinder M, Whitlow PL, Aker UT, Heuser RR, King SB, Kent KM, Leon MB, Kolansky DM, Sandza JG. Rapid arterial hemostasis and decreased access site complications after cardiac catheterization and angioplasty: results of a randomized trial of a novel hemostatic device. J Am Coll Cardiol 1995; 25:1685-1692.

11. Gershony G, Brock JM, Powell JS. Novel vascular sealing device for closure of percutaneous vascular access sites. Cathet Cardiovasc Diagn 1998;45:82-88.

12. Gerckens U, Cattelaens N, Muller R, Lampe EG, Grube E. Percutaneous suture of femoral artery access sites after diagnostic heart catheterization and or coronary intervention. safety and effectiveness of a new arterial suture technic. Herz 1998;23:2734.

13. Gerckens U, Cattelaens N, Lampe EG, Grube E. Management of arterial puncture site after catheterization procedures: evaluating a suture-mediated closure device. Am J Cardiol 1999;83:16581663.

14. Baim DS, Knopf WD, Hinohara T, Schwarten DE, Schatz RA, Pinkerton CA, Cutlip DE, Fitzpatrick M, Ho KK, Kuntz RE. Suture-mediated closure of the femoral access site after cardiac catheterization: results of the Suture to Ambulate and Discharge (STAND I and STAND II) trials. Am J Cardiol 2000;85:864-869.

15. Wetter DR, Rickli H, von Smekal A, Amann FW. Early sheath removal after coronary artery interventions with use of a suturemediated closure device: clinical outcome and results of Doppler US evaluation. J Vasc Intervent Radiol 2000;11:1033-1037. 
16. Cohen DJ. Understanding and evaluating the cost-effectiveness of new coronary interventions. J Invas Cardiol 1997;9(Suppl D): 24D-27D.

17. Cohen DJ. Outpatient transradial coronary stenting: implications for cost-effectiveness. J Invas Cardiol 1996;8(Suppl D):36D-39D.

18. Rogers EW, Doty WD, Stewart J. Significant improvements in patient care and cost savings resulting from percutaneous vascular surgery (PVS). J Cardiovasc Manag 1999;10:13-17.

19. Silber S, Gershony G, Schon B, Schon N, Jensen T, SchrammW. A novel vascular sealing device for closure of percutaneous arterial access sites. Am J Cardiol 1999;83:1248-1252.

20. Chamberlin JR, Lardi AB, McKeever LS, Wang MH, Ramadurai G, Grunenwald P, Towne WP, Grassman ED, Leya FS, Lewis BE,
Stein LH. Use of vascular sealing devices (VasoSeal and Perclose) versus assisted manual compression (Femostop) in transcatheter coronary interventions requiring abciximab (ReoPro). Cathet Cardiovasc Intervent 1999;47:143-147.

21. Wilentz JR, Mishkel G, McDermott D, Ravi K, Fox JT, Reimers $\mathrm{CD}$, Maydick S. Outpatient coronary stenting: femoral approach with vascular sealing. Herz 1999;24:624-633.

22. BVMed annual report 1999/2000 (www.bvmed.de 2001).

23. Cohen DJ, Breall JA, Ho KK, Weintraub RM, Kuntz RE, Weinstein MC, Baim DS. Economics of elective coronary revascularization. comparison of costs and charges for conventional angioplasty, directional atherectomy, stenting and bypass surgery. J Am Coll Cardiol 1993;22:1052-1059. 